\title{
2006-692: THE IET IN SERVICE INDUSTRIES
}

\section{Donna Summers, University of Dayton}

Donna C.S. Summers, Ph.D. is a professor of Industrial Engineering Technology at the University of Dayton. Her major areas of concentration are Quality Assurance and Human Factors. She has published two texts: Quality and Quality Management, both by Prentice Hall. She holds a BSME from University of Cincinnati and an MSIE from Purdue University. She obtained her Doctorate in Industrial Engineering from the University of Cincinnati. 


\title{
The IET in Service Industries
}

\begin{abstract}
Were you aware that consumers spend $60 \%$ of their dollars on services versus only $12 \%$ on durable goods? These statistics underscore data showing that in the past 10 years employment in manufacturing sector has declined from over $17 \%$ to just $11 \%$, while employment in health care, logistics, and other service industries has risen from $13 \%$ to $17 \%$.

Recent articles in a wide variety of publications, discuss the carry-over of industrial engineering technology tools and techniques from manufacturing to the service industries. Industrial Engineering Technology courses focus on the goals of improving productivity, quality, and safety while reducing costs. Since these goals are suited to any industry, regardless of its economic sector, students in the Industrial Engineering Technology program are uniquely suited to transition from employment opportunities in manufacturing industries to employment opportunities in service enterprises.
\end{abstract}

IET programs have always been known for maintaining excellence through innovative courses, class activities, and the exploration of new fields of opportunity. Now more than ever, IET programs need to expand their knowledge and use of service industry applications. As global competition continues to grow and U.S. service industries multiply, our IET graduates should be poised to meet the challenges unique to the service industries.

The purpose of this paper is to discuss the changes necessary to enable IET programs to seriously integrate topics from healthcare, logistics, e-business, and other service industries into its core courses. It will also discuss how curricula changes will enhance students' skill set, increase the variety of their job opportunities upon graduation, and enable us to market our programs more effectively to a broader range of potential students in the future.

\section{Where are we now? Faculty}

\section{Silla valin tyoasioita junailee eteenpain}

Can you translate this survey response? Neither could we. While this reply to our request for service industry information left us wondering, after compiling the results of our surveys, to a certain extent, this particular response sums up the all the answers. Service industry applications haven't translated well into course exercises or examples.

Though the intended focus of this paper was Industrial Engineering Technology, our twenty-three 2005 ET ListServe survey respondents were from a wide variety of disciplines, including manufacturing, mechanical, industrial, electrical, HVAC and construction engineering technology. The questions included: 
3. Do you track service industry job placement among your graduates?

Yes 2 No 20

4. Do you have any courses or portions of courses dealing with service industries?

Yes 9 No 12

5. Have you made any changes to your curriculum to include service industry topics? Yes 8 No 13

6. Do you have examples/cases specifically dealing with service industries to share with your students? Yes 11 No 11

7. Do any of your course projects take place in a service industry?

Yes 10 No 21

While only one or two schools did any tracking of student placement in service industry jobs, some of the respondents specifically mentioned including service industry applications, examples, or cases in their courses. The email respondents included service industry examples and exercises because their own work experience included service firms such as logistics, schools, hospitals, and government.

Taking the broader view of engineering technology in the service industries, there are many applications for all majors. Some examples included disaster relief efforts involving multiple engineering disciplines; satellite data management, data pattern detection, voice creation and speech identification, FBI information gathering, and malaria tracking using the skills of electronic and computer engineering technology; green buildings and HVAC for service industries for construction and HVAC engineering technology; supply chain management, medical improvements, logistics and transportation, and leisure pursuits for industrial engineering technology. Applying engineering technology tools and techniques to the service industries makes sense. What organization wouldn't want to benefit from improvements these tools and techniques can provide?

\section{Where are we now? Students}

In April of 2005, we surveyed U.D. engineering technology students to determine their interest in service industry topics. The survey asked three questions:

1. Have you considered working in the service industries (hospitals, banks, government, logistics, food services, transportation, etc.) upon graduation?

2. Would you be interested in taking a course entitled IET Applications in the Service Industries?

3. Would you like to see more cases related to the service industries utilized in existing classes?

Student response was overwhelmingly positive, revealing to us that our students, regardless of their year, were fully aware of the changing job market. As the following comments show, they consider working in the service industries an interesting challenge. 
I am glad you have issued this survey. This topic has been on my mind for the longest time and I hope some provisions can be made to create this class.

I have often sat in my ET classes and had to ask myself, how would I apply this to the non-traditional engineering jobs that I will most likely consider? What job does this class qualify me for in the service industry, government, logistic, bank or hospital?

Yes, although I currently have a job in the semiconductor industry, I'm fully aware that many jobs are leaving the U.S. for China and India. My company has opened a facility in Suzhou, China even. Therefore, the U.S. is likely to become even more service oriented.

The service industry is where I have formed a lot of my conceptions about what I might be doing when I graduate. From my experience in retail it became clear to me that thing didn't run nearly as well as they could. Employees were often stressed and confused. Being able to help eliminate this would be something I would get a lot of satisfaction from. Another area I have always been interesting in is the Transportation industry. I have thought about working for a railroad or similar company. I've read that railroads have been more efficient and productive lately. I am interested in how that happened and I'm looking to gain some insight on how I could be an attractive employee and make further contributions to the industry.

I think that a class such as this would help IE's know the true potential of their education. I would definitely take a class like this because it would help me better understand how I can apply something like IE (mathematical) to industries that are not considered typical "engineering" settings - it would definitely help alleviate some of the anxiety when approaching these industries for job inquires and interviews. Excellent idea!

Yes, I think that most of the classes refer to automotive industries $80 \%$ of the time, which makes service industries kind of unknown for us when people talk about considering working in an environment like this. I think since [it] is not being talked that much, we are kind of afraid of not being able to work with it. If service industries are included in class discussions besides what is being discussed already, students will develop a larger knowledge on what is going on in other industries besides cars or manufacturing industries.

Absolutely! I have applied for internships and even had a co-op at a distribution center. I plan to choose a career in logistics or possibly a service industry. ... since our major is so broad, we need to broaden the examples used in our classes to help prepare or students for the various problems in the "real world". 
Sorry for the enthusiasm, but I really do wish that there were a course or courses that covered these topics within industrial engineering technology. That is my main interest, and I will probably be looking for a job after college in one of those fields. I believe that learning about these areas of business would help shape $U . D$. 's students into better managers and engineers. If there is anything I can do to help (i.e. focus groups, surveys, general input, etc.) please feel free to contact me. I have wanted our department to offer these classes or cover this material for some time. I am always happy to help with improving our department.

...even though I am getting my dual degree in manufacturing, I will more than likely be looking at government, logistics, hospitals and banks. I do not actually see myself in a manufacturing setting on a daily basis.

Well, I think that service improvement is a serious outlet of IET and again there aren't that many programs that even involve improving the quality of a service

\section{Where are we now? Publications}

In order to determine just how difficult it would be to come up with service industry examples for a variety of fields, a review was made of industry magazines from 20042005 that could be found in the U.D. engineering technology offices. Findings included IIE Industrial Engineering, IEEE Spectrum, SME Manufacturing Engineering, ASME Mechanical Engineering, Quality Progress, Bureau of Worker's Compensation Quarterly, Construction Management, IEEE Potentials, Quality Digest, and others. The search resulted in about 25 articles related to the application of engineering technology techniques to service industries. Not too bad until you contrast that with several hundred articles concerning manufacturing and design applications.

Service industry examples exist in every major industrial publication. Topics ranged from to hospitals and data technology to leisure and food service, to retail and warehousing to telecommunications and transportation. The review shows that it is possible to find published examples that can be used as examples in appropriate courses.

\section{Where are we now? Employment}

As mentioned earlier, only a very few universities and colleges track the service industry employment choices their graduates make. Although they do not track engineers in service industries specifically, Bureau of Labor Statistics (BLS) website provided the following information. The BLS tracks U.S. manufacturing employment and industrial production. As the following figure created from information from the Bureau of Labor Statistics and Federal Reserve Board shows, U.S. manufacturing production has decreased since 1978, while at the same time, until recently, the industrial production index has increased. While we, as a nation, are producing more, we are doing it with fewer people. 


\section{U.S. Manufacturing Employment versus Industrial Production Index, 1978-2003}

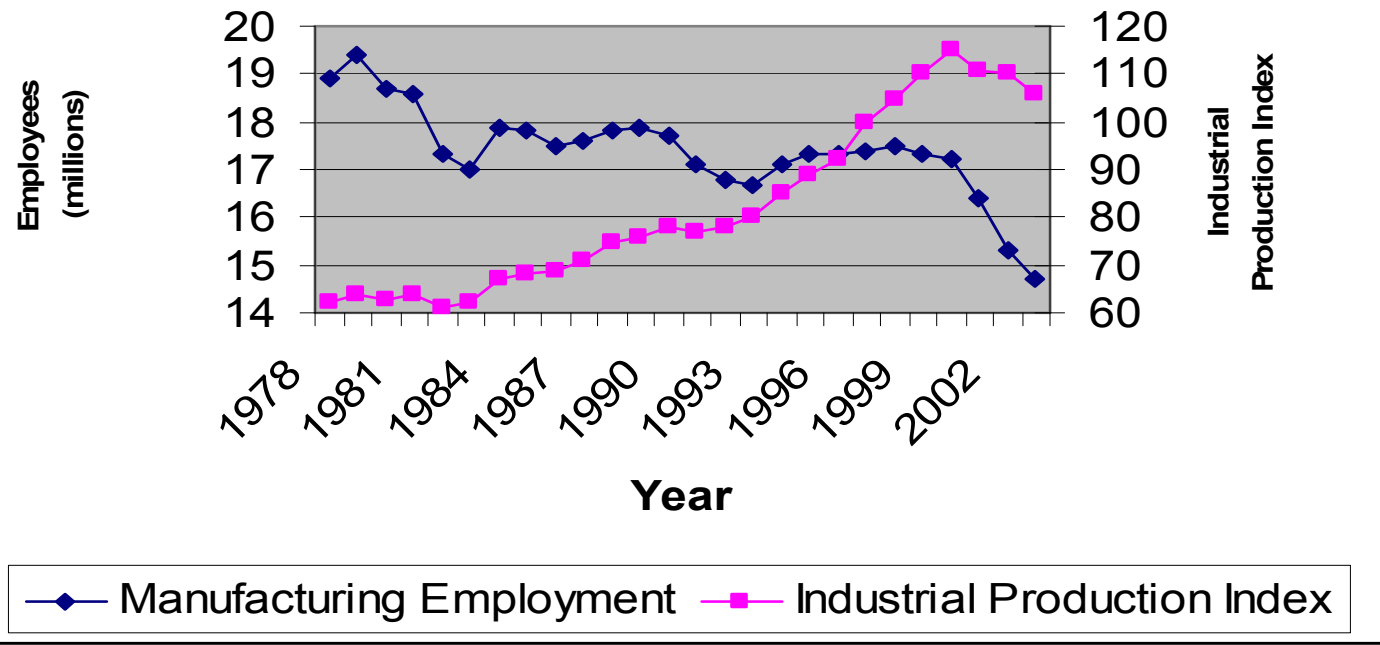

From 1994 to 2004, jobs in manufacturing have declined from 17,020,000to 14,330,000. By 2014, this number is expected to decline further to 13,553,000. Service providing jobs increased from 1994 to 2004, 92,292,000 to 110,374,000. Between 2004 and 2014, this number is expected to increase to $129,090,000$, another 18 million jobs. This doesn't include changes in Transportation/Warehousing (2004: 4,250,000; 2014: 4,756,000), Healthcare (2004: 14,187,000; 2014: 18,482,000), and Leisure/Hospitality (2004:

$12,479,000 ; 2014: 14,694,000)$. Government employment at the federal, state and local level is also expected to expand.

These statistics point to a growing service sector. People with engineering technology and engineering degrees will be needed in the service industries, adapting their knowledge and skills to the particular applications of the organization. The same HVAC design engineer who created clean rooms for manufacturing will be needed to create sterile or quarantine environments in hospitals. Computer and electrical engineers and engineering technologists will continue to be needed in digital filming and computer generated imaging in the film industry. Hospitals and offices need industrial engineering technology tools and techniques to improve processes and customer services.

Transportation and logistics opportunities will expand to support global movement of goods. It is critical to define new applications to engineering and engineering technology education and skill sets.

\section{What can we do to improve?}

Given the increase in the number of service industries in the United States, engineering technology can no longer rely solely on instructors who have service industry knowledge 
in their backgrounds. Serious review and development of curriculum needs to take place. This development should focus on answering questions like: does our faculty need more exposure to service industry applications? Yes. Do our students need more exposure to service industry applications related to their field of study? Yes. Do they need projects specifically designed to show how their learning can be used to enhance operations in a service industry such as logistics, transportation, airlines, hospitals, construction, and government? Yes. If you also determine that the answer to these questions is 'yes', then you'll need to develop a plan of action to integrate service industry applications into your curriculum.

Having made the decision that the IET program at the University of Dayton should respond to the need to educate our students about service industry applications, we have embarked upon curriculum development. We considered two approaches: a separate course titled: The IET in Service Industries; or integrating service industry applications into each of our courses. After discussing the impact of such changes, such as curriculum rearrangement, course loads, and the impact of service industry examples on non-IET students, we opted to integrate. Integration will be accomplished through the development of course appropriate examples and projects, the creation of a speaker list related to course materials, and enhancing industry contacts for tour, internship, co-op, and projects opportunity. We feel that much improvement can be made to our existing curricula by taking three straightforward steps:

Establish connections with service industries in your area. Investigate how they use the skills and techniques you teach to solve their problems.

Increase the number of student projects involving interaction with service industries.

Increase the number of examples, cases and plant tours related to service industry applications.

There is little doubt that service industries are on the rise in the U.S. What needs to improve is our understanding that any organization, whether manufacturing, construction, service, or government can benefit from engineering technology tools and techniques. After all, what organization wouldn't want fewer defects, better quality, more accurate costing, lower costs, higher efficiencies, shorter and more predictable lead-times, increased job satisfaction, lower turnover, and lower absenteeism?

\section{Bibliography}

Averett, S. A Home for Efficiency: Lean Green Common Sense Construction, Industrial Engineer, March 2003, Vol. 35, Vol. 3, p. 26-33.

Averett, S. His Beautiful Launderettes, IIE Solutions, April 2005, Vol. 37, No. 4, p. 30-35.

Averett, S. St. Michael Rising, Industrial Engineer, August 2003, Vol. 35, No. 8, p. 28-33. 
Averett, S. The Elephant in the Room: The State of Manufacturing in America, Industrial Engineer, January 2004, Vol. 36, No. 1, p.26-33.

Bureau of Labor Statistics http://stats.bls.gov

Elliot, M. To Serve and Protect, IIE Solutions, IIE Solutions, September 2002, Vol. 34, No. 9, p. $26-32$.

Elliot, M. Road Warrior, IIE Solutions, August 2002, Vol. 34, No. 8, p. 24-28.

Gluck, R. Steering Students Toward Science and Engineering, The IEEE Institute, September 2005 , Vol. 29, No. 3. p.1.

Hyer, N. and Wemmerlov, U. The Office That Lean Built, IIE Solutions, October 2002, Vol. 34, No. 10, p. 37-43.

Patton, F. Does Six Sigma Work in Service Industries? Quality Progress, September 2005, Vol. 38, No. 9, p. 55-60.

Manajan, V. American Manufacturing is Not Dead, Industrial Engineer, January 2004, Vol. 36, No. 1, p.24. Sayle, A. Opportunities are Everywhere, Quality Progress, April 2005, Vol. 38, No. 4, p. 33-38. 